Mauerschau - Die DDR als Film 



\section{Mauerschau - Die DDR als Film}

Beiträge zur Historisierung eines verschwundenen Staates

Herausgegeben von

Dominik Orth und Heinz-Peter Preußer 
Gedruckt mit freundlicher Unterstützung der Fakultät für Geistes- und Kulturwissenschaften der Bergischen Universität Wuppertal, des UniService Transfer der Bergischen Universität Wuppertal sowie des Prorektorates für Forschung, Drittmittel und Graduiertenförderung der Bergischen Universität Wuppertal.

ISBN 978-3-11-062724-4

e-ISBN (PDF) 978-3-11-062940-8

e-ISBN (EPUB) 978-3-11-062756-5

\section{Library of Congress Control Number: 2020932201}

\section{Bibliografische Information der Deutschen Nationalbibliothek}

Die Deutsche Nationalbibliothek verzeichnet diese Publikation in der Deutschen Nationalbibliografie; detaillierte bibliografische Angaben sind im Internet über http://dnb.dnb.de abrufbar.

(c) 2020 Walter de Gruyter GmbH, Berlin/Boston Coverabbildung: Berlin Wall in the evening/Pixelklex/Dreamstime.com Satz: Integra Software Services Pvt. Ltd.

Druck und Bindung: $\mathrm{CPI}$ books $\mathrm{GmbH}$, Leck

www.degruyter.com 